\title{
A PERCEPÇÃO DO PROFESSOR DE BIOLOGIA E A SUA FORMAÇÃO: A EDUCAÇÃO AMBIENTAL EM QUESTÃO
}

\section{The perception of the teacher of biology and its formation: environmental education in question}

Simone Sendin Moreira Guimarães ${ }^{1}$ Edson do Carmo Inforsato ${ }^{2}$

Resumo: O presente artigo apresenta os resultados de uma pesquisa cujo objetivo foi identificar as percepções dos professores de Biologia do município de Piracicaba, SP, e dos alunos concluintes de um curso de licenciatura em Ciências Biológicas em relação à presença da Educação Ambiental em sua formação inicial, a fim de discutir a inserção da temática na universidade em geral e, especificamente, na licenciatura em Ciências Biológicas. Os resultados indicam que o professor de Biologia ainda necessita de uma formação mais crítica em relação à educação ambiental e que, numa perspectiva complexa, essa formação necessita ser tratada de forma mais rigorosa na universidade e nas licenciaturas em Ciências Biológicas para que os profissionais formados possam atuar, efetivamente, na formação cidadã para uma sociedade mais sustentável.

Palavras-chave: Formação de professores. Educação Ambiental. Ensino de Biologia. Ensino Superior.

\begin{abstract}
The article shows the results of a survey aimed at identifying the perceptions of Biology teachers from Piracicaba, SP, and of graduating Biological Sciences students. The presence of environmental education in their initial training is investigated in order to discuss the introduction of the theme at the university in general and specifically in the Biological Sciences. The results indicate that the biology teachers still need more critical environmental education training and this training, from a complex perspective, needs to be intense in order that degreed professionals can effectively act in civic education for a more sustainable society.
\end{abstract}

Keywords: Teacher training. Environmental education. Biology teaching. Higher education.

\footnotetext{
${ }^{1}$ Laboratório de Estágio Supervisionado e Ensino de Ciências, Instituto de Ciências Biológicas, Universidade Federal de Goiás. Campus Samambaia, Caixa Postal 131. Goiânia, GO, Brasil. 74.001-970. sisendin@ig.com.br ${ }^{2}$ Programa de Pós-Graduação em Educação Escolar, Faculdade de Ciências e Letras, Universidade Estadual Paulista "Júlio de Mesquita Filho" (Unesp). Araraquara, SP, Brasil.
} 


\section{Introdução}

Há quase quarenta anos, o mundo discute sobre os problemas ambientais globais e a instalação de uma crise ambiental. Porém, hoje, percebemos que pouca coisa mudou em relação aos encaminhamentos mundiais sobre a crise ambiental que assola nosso planeta. O problema, considerado secundário ao longo desses anos, hoje assusta grande parte das pessoas. Alterações climáticas significativas intensificam-se e nos fazem pensar em como o ser humano conseguiu, em tão pouco tempo, alterar os sistemas de uma maneira tão drástica, que talvez inviabilize a vida de muitas espécies - inclusive a nossa. Hoje, neste início de século XXI, várias crises se entrelaçam, e a crise ambiental é a mais planetária de todas elas.

Para a superação da crise ambiental, há necessidade da superação do saber científico compartimentalizado, superespecializado. Há, portanto, a necessidade de uma produção epistemológica contemporânea em ciência e a necessidade de formar "ambientalmente" profissionais que, por sua atividade, interfiram de alguma maneira na qualidade do meio ambiente, até porque, em última instância, é a qualidade do meio ambiente que vai garantir a qualidade de vida em uma sociedade mais justa.

A importância dessa formação ambiental não é novidade, pois, em todo o histórico da crise ambiental, a educação tem sido lembrada como uma dinâmica capaz de responder positivamente a essa problemática, ao lado de outros meios: políticos, econômicos, legais, científicos, éticos e técnicos (LIMA, 2002). Nesse sentido, é urgente que a universidade e os cursos, em especial os de licenciatura, revejam seus valores e reorientem as atividades acadêmicas e de pesquisa para que essas, a partir de uma educação que seja ambiental, levem em conta a construção de um saber ambiental consistente. Estamos em plena década da Educação para o Desenvolvimento Sustentável (período 2005-2014) (UNESCO, 2004) e, em que pese a quantidade de discursos sobre o tema, todo o sistema formativo humano tem atuado de maneira muito tímida em relação a essa temática.

A crise ambiental, atrelada à crise do conhecimento científico, exige um novo papel das universidades e dos cursos de formação de professores. Essas são convocadas a assumirem um posicionamento reflexivo e crítico, a fim de se construir uma nova racionalidade que induza à transformação dos paradigmas científicos tradicionais, promova novos tipos de conhecimentos e integre diferentes saberes, com a participação da sociedade (MORALES, 2007). Riojas (2006) alerta que a complexidade dos problemas ambientais supõe uma reconceituação epistemológica, pedagógica e estrutural da universidade e dos cursos presentes em sua estrutura.

De acordo com Santos (2001), a universidade foi sempre acusada de raramente ter mobilizado os conhecimentos acumulados a favor dos problemas sociais. Hoje, a universidade precisa, com urgência, exercer seu papel social perante os problemas do mundo contemporâneo. E não os há em maior escala do que os problemas ambientais.

${ }^{3}$ Sob coordenação da Unesco, essa iniciativa das Nações Unidas, instituída por resolução de sua Assembleia Geral, procura estabelecer um grande plano internacional de implementação de mudanças, tendo como referência os preceitos da Agenda 21 (LAYRARGUES, 2004). 
Para Morin (2001), a universidade conserva, memoriza, integra, ritualiza uma herança de saberes, valores, ideias etc.. Ela regenera essa herança ao reexaminá-la e atualizá-la, gerando, assim, saberes, ideias e valores que passam a fazer parte dessa herança. Não há, ainda, uma herança relacionada às questões ambientais. É necessário reexaminar e atualizar alguns valores ambientais que são discutidos dentro da universidade, modificar práticas de formação e de gestão adotadas na universidade, para que essa não caia na cilada do ditado "faça o que eu digo, mas não faça o que eu faço".

O autor esclarece que, no século XIX, a universidade soube responder ao desafio do desenvolvimento das ciências, sobretudo, criando departamentos onde foram introduzidas as ciências modernas. Porém, a partir dessa departamentalização, "a Universidade faz com que coexistam - mas não que se comuniquem - as duas culturas: a das humanidades e a cultura científica" (MORIN, 2001, p. 81-82). Isso se torna um problema em relação à construção de um saber ambiental, que não faz parte apenas das humanidades ou da cultura científica, mas, sim, é parte das duas ao mesmo tempo.

Para Bursztyn (2004), a universidade, ao longo do século XX, seguiu uma trajetória crescentemente especializante. Agora, no início do século XXI, deve atentar para a revisão de sua trajetória, diante do desafio de cumprir seu papel de oferecer novas respostas às novas perguntas que o mundo real apresenta. Ainda para o autor (BURSZTYN, 2001), a relação da universidade com as questões associadas ao meio ambiente foi muito difícil, pois essa dualidade e a organização por departamentos, característica histórica da estrutura universitária, tendem a valorizar as especificidades e deixar de lado as posições pluralistas. Muitas vezes, as propostas interdisciplinares ficaram sem um local que as acolhesse. Assim, o tema meio ambiente, considerado como base para se enfrentar o desafio do desenvolvimento sustentável, chega à universidade a partir de contextos departamentalizados. Nas palavras do autor, o "adjetivo ambiental começa a aparecer acoplado a várias disciplinas: engenharia ambiental, direito ambiental, Educação Ambiental, sociologia ambiental, história ambiental [...]" (BURSZTYN, 2001, p. 14), e essa adjetivação pode não dizer muita coisa se, embora coexistindo, essas disciplinas não se comunicarem. Não mais é possível que ciências que sejam ambientais se espremam em vazios epistemológicos entre as ciências sociais e da natureza, apenas adjetivando disciplinas existentes. É necessário, como dito anteriormente, que esse saber construído seja interdisciplinar (ROHDE, 2001)

Embora a universidade "não pareça preparada para defrontar os desafios, tanto mais que esses apontam para transformações profundas e não para simples reformas parcelares" (SANTOS, 2001, p. 187), e apesar do impacto desse surgimento departamentalizado, vemos a introdução de uma educação voltada para o ambiente, na universidade, como uma prática indispensável para se trabalharem valores e conceitos, além de desenvolver atitudes e aptidões para que graduandos, em especial os licenciandos, possam adotar uma posição crítica e, ao mesmo tempo, participativa, em relação aos complexos problemas ambientais, firmando um compromisso com a melhoria da qualidade de vida de todos.

A educação universitária, em especial a licenciatura, deve assumir a sua responsabilidade, para que a Educação Ambiental seja incorporada à educação geral, começando pela infantil. É preciso que professores sejam, primeiramente, formados em outras bases, com uma percepção que ultrapasse a manipulação de conteúdos ecológicos, e que também supere a simples aplicação de técnicas ecológicas. Nem é lógico exigir que um professor trabalhe ideias, 
conceitos, valores, habilidades e atitudes que colaborem com a formação de uma sociedade ambientalmente responsável, se ele não foi assim formado e nem recebeu uma formação continuada para isso.

Assim, a partir dos pressupostos discutidos, o objetivo desse trabalho foi identificar as percepções dos professores de Biologia do município de Piracicaba, SP, e dos alunos concluintes de um curso de licenciatura em Ciências Biológicas, do mesmo município, em relação à presença da Educação Ambiental em sua formação inicial.

Na primeira parte da pesquisa, a amostra contou com 24 professores de escolas públicas e particulares do município e 24 formandos de um curso de Ciências Biológicas. O instrumento utilizado foi um questionário semiestruturado, com questões abertas sobre a presença da temática ambiental na formação inicial de professores e formandos. Os dados foram tabulados e discutidos à luz do referencial teórico adotado.

$\mathrm{Na}$ segunda parte, duas questões geradoras foram utilizadas e quatro professores e quatro formandos foram entrevistados. O desenvolvimento metodológico dessa etapa da pesquisa foi feito pela abordagem qualitativa, a partir de uma adaptação da Análise de Conteúdo de Bardin (1977) feita por Porto, Simões e Moreira (2004). A escolha levou em consideração que esse tipo de metodologia tem como objetivo central desvelar o fenômeno investigativo, "resgatando atitudes muitas vezes inconsistentes, que se manifestam por tomadas de posição, de qualificações, de descrições e de designações de avaliações com significados importantes ou não" (PORTO; SIMOES; MOREIRA, 2004, p. 108).

\section{As percepções dos professores}

Nessa primeira etapa da pesquisa, duas questões foram feitas aos professores e alunos pesquisados. Os resultados foram tabulados e originaram os gráficos 1 a 4, que são apresentados e discutidos a seguir.

Gráfico 1. Sobre a percepção em relação à presença da discussão sobre Educação Ambiental na formação inicial

Acredita ter discutido sobre Educação Ambiental na formação inicial? (professores)

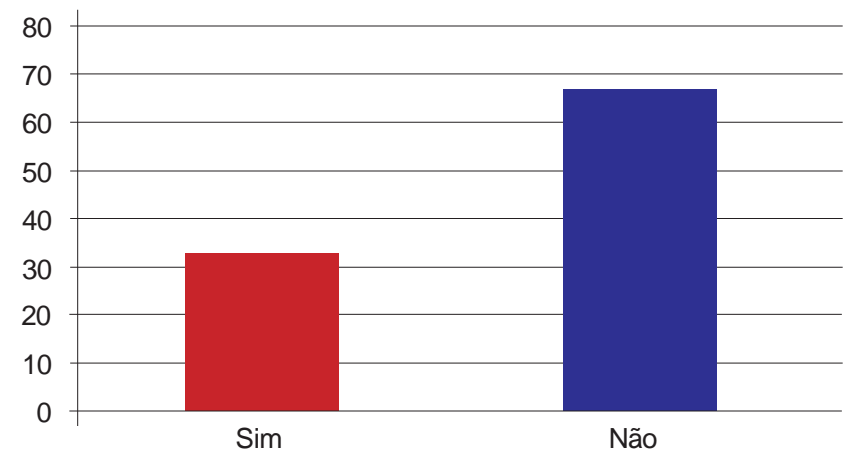

Fonte: Elaborado pelos autores 
A percepção do professor de Biologia ...

Gráfico 2. Sobre a percepção em relação à presença da discussão sobre Educação Ambiental na formação inicial

Acredita ter discutido sobre Educação Ambiental na formação inicial? (formandos)

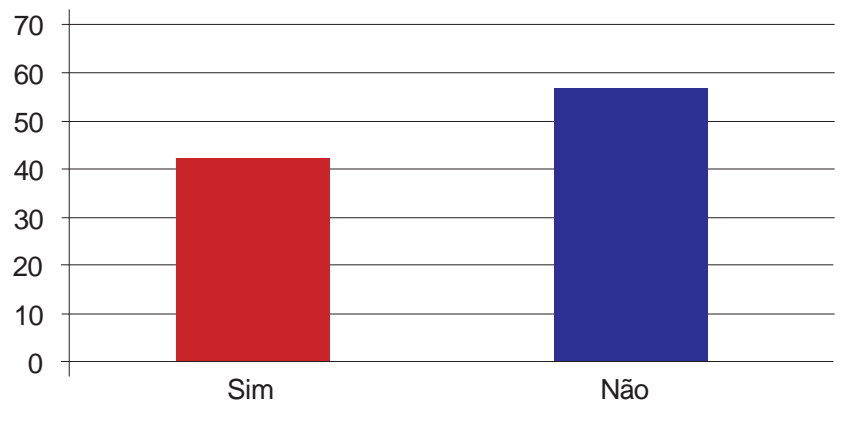

Fonte: Elaborado pelos autores

Gráfico 3. Sobre a(s) disciplina(s) em que discutiu de maneira sistemática sobre Educação Ambiental (Professores)

Em que disciplina discutiu sobre Educação Ambiental? (professores)

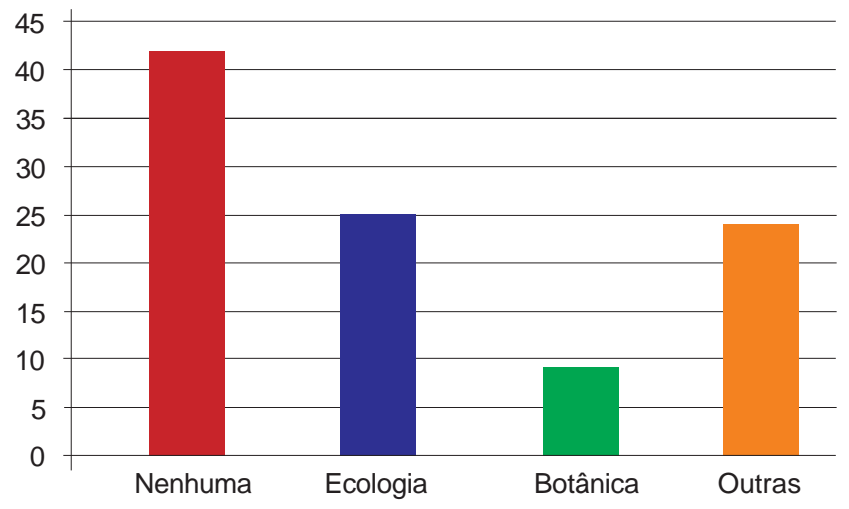

Fonte: Elaborado pelos autores 
Gráfico 4. Sobre a(s) disciplina(s) em que discutiu de maneira sistemática sobre Educação Ambiental (Formandos)

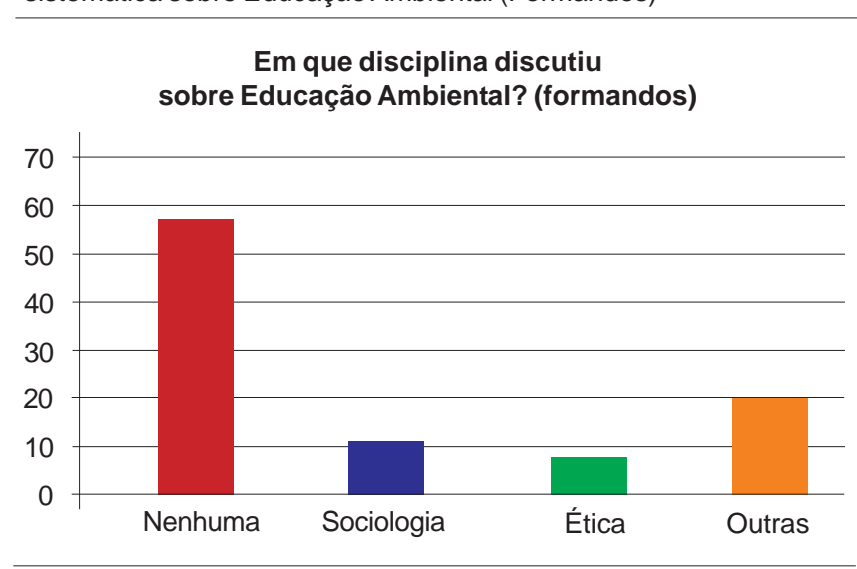

Fonte: Elaborado pelos autores

Inicialmente, podemos perceber que mais da metade dos professores (67\%) alegam não terem discutido sistematicamente sobre o tema na sua formação inicial, e $43 \%$ indicam que não discutiram sobre o tema em nenhuma disciplina na graduação, índice bem próximo ao dos formandos. Em relação a esses, 58\% dos alunos alegaram não ter discutido sistematicamente o tema em nenhuma disciplina do curso.

Os professores que relatam ter discutido o tema ambiental em uma disciplina específica, na sua maioria, indicam a disciplina de ecologia como aquela onde isto se deu. Tal fato pode ter ocorrido em virtude do currículo antigo a que esses professores foram submetidos ou em virtude da "confusão" que ainda fazemos entre ecologia e Educação Ambiental.

Odum (1988) esclarece que a ecologia é um campo reconhecidamente distinto da ciência desde 1900. A expressão deriva do grego oikos (casa) e logos (estudo). Assim, a ecologia seria o estudo do "ambiente da casa", e isso "inclui todos os organismos contidos nela e todos os processos funcionais que a tornam habitáveis" (ODUM, 1988, p. 1). Embora essa ciência dê vários subsídios para a Educação Ambiental, não leva em conta aspectos sociais, políticos e econômicos formativos da mesma maneira que a Educação Ambiental. Além disso, no final da década de 1970, desconsiderando os acontecimentos de Estocolmo e Tbilisi, o Ministério da Educação (MEC) publica o documento "Ecologia - uma proposta para o ensino de $1^{\circ}$ e $2^{\circ}$ graus" (DIAS, 2004), como uma contribuição às discussões sobre Educação Ambiental na época, evidenciando, deste modo, a confusão que o Ministério da Educação fazia com as áreas, o que influenciou a formação de muitos profissionais.

Para Dias (2004), tal proposta representava um retrocesso, por sua abordagem reducionista, na qual a Educação Ambiental ficaria acondicionada no pacote das ciências biológicas. Ainda para o autor, isso servia a interesses internacionais que não queriam uma abordagem que considerasse aspectos sociais, culturais, econômicos, éticos e políticos da questão ambiental.

Essa abordagem foi considerada, já na época, um escândalo tanto nos meios ambientalistas quanto nos meios educacionais brasileiros envolvidos com a Educação Ambiental, a 
A percepção do professor de Biologia ...

despeito de muitas instituições adotarem a proposta sem muita crítica ou discussão. Ainda hoje, alguns cursos incluem a abordagem da Educação Ambiental apenas dentro da ecologia. A propósito, das grades curriculares observadas nessa pesquisa (em virtude da formação dos professores entrevistados), podemos citar o exemplo de uma instituição de grande porte de Campinas que ainda apresenta a abordagem da Educação Ambiental vinculada à ecologia na disciplina: "Ecologia e Educação Ambiental". Porém, chama-nos a atenção a indicação da disciplina "Projetos em Educação Ambiental", citada por uma professora. A professora indicou que essa disciplina não fez parte da sua formação em biologia, mas que ela procurou a complementação em uma universidade pública de Piracicaba, SP, onde a disciplina fazia parte do currículo de Agronomia e Engenharia Florestal, como disciplina optativa. Atualmente, essa disciplina faz parte da matriz curricular do Curso de Biologia dessa instituição.

Em relação aos alunos formandos, a maior parte acredita que não discutiu sobre o tema em nenhuma disciplina do curso (54\%). Já em relação aos alunos que indicaram uma disciplina, a disciplina que mais é citada como a que trabalhou o tema na graduação foi a sociologia (17\%). Outras sete disciplinas também foram citadas pelos alunos. Esse resultado pode indicar que a temática já começa a ser inserida em algumas disciplinas dentro do curso, porém de maneira assistemática. Além disso, muitas vezes, nas disciplinas da área da licenciatura ou das ciências humanas, o trabalho por projetos estimula a escolha do tema por alunos que têm afinidade com a temática ambiental. Dois alunos investigados indicaram que, embora tenham discutido sobre o tema na formação inicial, essa discussão não aconteceu em disciplinas do curso, mas em minicursos realizados durante a Semana de Estudos do curso.

Para a segunda etapa da pesquisa, professores e formandos foram convidados via email, e os primeiros a responderem positivamente ao convite foram entrevistados. A amostra foi de $17 \%$ em relação ao número de indivíduos da primeira etapa da pesquisa. As entrevistas realizadas (gravadas) foram transcritas e as respostas às questões formuladas foram analisadas sob a ótica dos pressupostos metodológicos elaborados pela técnica escolhida (PORTO; SIMÕES; MOREIRA, 2004), pois, através de manifestações de juízo de valores, o ser humano, em sua maneira espontânea de falar, opina sobre fenômenos que pensa conhecer. As unidades de significado foram tabuladas e são apresentadas a seguir (tabelas 1 e 2).

Unidades de significado - Professor - Questão 1 Qual foi seu primeiro contato com a Educação Ambiental?

Tabela 1. Questão 1 - Primeiro contato com Educação Ambiental - Professor

\begin{tabular}{|c|c|c|c|c|c|}
\hline Sujeito (professor) & 1 & 2 & 3 & 4 & Total \\
\hline Na própria prática profissional (depois da formação) & $x$ & $x$ & & & 2 \\
\hline Na universidade não foi (formação inicial). & $\mathrm{x}$ & $\mathrm{X}$ & $\mathrm{X}$ & $\mathrm{X}$ & 4 \\
\hline Antes da formação universitária (no Ensino Fundamental ou Médio) & & & $\mathrm{X}$ & $\mathrm{x}$ & 2 \\
\hline Com o professor de ciências/ biologia no parque ecológico, praça, horta & & & $\mathrm{X}$ & $\mathrm{x}$ & 2 \\
\hline Juntando conhecimentos de várias disciplinas (na profissão) & $\mathrm{x}$ & & & & 1 \\
\hline $\begin{array}{l}\text { Conversando com professor sobre plantio de árvores, preservação dos } \\
\text { rios, sobre como não poluir }\end{array}$ & & & & $\mathrm{x}$ & 1 \\
\hline
\end{tabular}

Fonte: Elaborada pelos autores 
Unidades de significado - Formando - Questão 1

Qual foi seu primeiro contato com a Educação Ambiental?

Tabela 2. Questão 1 - Primeiro contato com Educação Ambiental - Formando

\begin{tabular}{|c|c|c|c|c|c|}
\hline Sujeito (formando) & 1 & 2 & 3 & 4 & Total \\
\hline Quando criança, no Ensino Fundamental & $\mathrm{x}$ & & & & 1 \\
\hline No Ensino Médio & & & & $\mathrm{x}$ & 1 \\
\hline Na Graduação & & $x$ & $\mathrm{x}$ & & 2 \\
\hline Aula de preservação no horto florestal (não cortar árvore ou fazer mau uso da água) & $\mathrm{x}$ & & & & 1 \\
\hline
\end{tabular}

Fonte: Elaborada pelos autores

Nessa questão podemos observar que o principal ponto de convergência entre os professores foi em relação à negação do contato com a temática da Educação Ambiental na universidade. Como nesse grupo os professores têm datas de formação distintas (1989; 1995; 2007 e 2008), obtemos um ponto de convergência, mas, com motivos diferentes. Metade (formadas em 1989 e 1995) afirma que o primeiro contato com a Educação Ambiental se deu na sua prática profissional, depois de formadas. Já as professoras formadas recentemente, indicam que o primeiro contato aconteceu antes da universidade, no Ensino Fundamental e Médio. Porém, o que elas caracterizam como atividades de Educação Ambiental ainda são atividades relacionadas a saídas de campo, em parques, bosques e praças, bem como a organização de hortas escolares. Essas atividades são relevantes no sentido de sensibilizar os alunos para questões relacionadas ao ambiente natural, mas deixam de lado questões culturais (sociais, econômicas, políticas etc.) muito importantes. Uma questão muito desconsiderada nas atividades ambientais escolares é a questão do modelo de produção e consumo.

Bem antes do neoliberalismo, o sistema capitalista se infiltrou na nossa maneira de pensar, produzir e consumir. Em nome desse sistema, a humanidade sacrificou muitas coisas. No Brasil, danificamos o cerrado (e, agora, a Amazônia) para a monocultura bilionária (que rende a poucos) (LEROY; PACHECO, 2006). Permitimos que nossa qualidade de vida seja comprometida por produtos químicos nocivos acrescentados aos alimentos e à água, sem que a relação entre a diminuição da qualidade de vida versus produção e consumo de químicos tóxicos seja estabelecida. Sofiatti $(2002$, p. 43) indica que "a relação de causa e efeito entre a ingestão de alimentos contaminados quimicamente e o desenvolvimento de processos carcinogênicos, mutagênicos e teratogênicos é de difícil estabelecimento, uma vez que se processa ao longo de muitos anos".

Entre os formandos, o maior ponto de convergência aconteceu em duas situações. Metade dos formandos indica que seu primeiro contato com o tema foi na Educação Básica, e a outra metade indica que esse contato inicial aconteceu na graduação. Isso também é corroborado pelo primeiro questionário aplicado, onde, aproximadamente, $50 \%$ dos alunos entrevistados indicam ter discutido sobre Educação Ambiental na graduação.

Um formando indicou ter tido contato, pela primeira vez, com Educação Ambiental antes da graduação; aponta, assim como os professores, que ela foi abordada dentro de uma perspectiva conservacionista. 
A percepção do professor de Biologia ...

$\mathrm{Na}$ questão 2, novamente, observamos a divisão nas posições apresentadas pelas professoras entrevistadas (tabelas 3 e 4). Metade indica que, em nenhuma disciplina, teve contato com o tema Educação Ambiental. Porém uma professora que faz essa afirmativa, depois, considera que o tratamento foi dado "um pouco" na disciplina sobre Botânica. A seguir, indica acreditar que a pouca abordagem do tema se deveu ao fato de seu curso (licen-

Unidades de significado - Professor - Questão 2

No curso de graduação você teve contato com esse tema? O que foi dito?

Quais disciplinas trabalharam o tema e como foi trabalhado?

Tabela 3. Questão 2 - Contato com o tema na graduação - Professor

\begin{tabular}{|c|c|c|c|c|c|}
\hline Unidades de significado & 1 & 2 & 3 & 4 & Total \\
\hline Não & $x$ & $x$ & & & 2 \\
\hline Muito pouco na botânica & $x$ & & & & 1 \\
\hline $\begin{array}{l}\text { Muita disciplina da área de licenciatura e pouca da área ambiental, então, } \\
\text { não teve Educação Ambiental }\end{array}$ & $x$ & & & & 1 \\
\hline Sim & & & $x$ & $\mathrm{X}$ & 2 \\
\hline Ecologia e botânica (como agir em relação ao ambiente) & & & $\mathrm{X}$ & & 1 \\
\hline $\begin{array}{l}\text { Didática das Ciências, Estágio (trabalho sobre conscientização, consumo } \\
\text { consciente) }\end{array}$ & & & $\mathrm{x}$ & & 1 \\
\hline $\begin{array}{l}\text { Psicologia da Educação (como se portar para demonstrar, aos alunos, } \\
\text { sobre Educação Ambiental) }\end{array}$ & & & & $\mathrm{X}$ & 1 \\
\hline
\end{tabular}

Fonte: Elaborada pelos autores

Unidades de significado - Formando - Questão 2

No curso de graduação você teve contato com esse tema? O que foi dito?

Quais disciplinas trabalharam o tema e como foi trabalhado?

Tabela 4. Questão 1 - Primeiro contato com Educação Ambiental - Formando

\begin{tabular}{|c|c|c|c|c|c|}
\hline Sujeito (formando) & 1 & 2 & 3 & 4 & Total \\
\hline Não. & $x$ & & $x$ & $x$ & 3 \\
\hline Teve, mas nada específico. & & $x$ & & & 1 \\
\hline Só no trabalho de conclusão de curso (TCC) & $x$ & & $x$ & & 2 \\
\hline Professores de didática e sociologia trouxeram textos & & $x$ & & & 1 \\
\hline Ecologia como Educação Ambiental & & & $x$ & & 1 \\
\hline Só na palestra na Serbio (Semana de Estudos do Curso de Biologia) & & & & $x$ & 1 \\
\hline
\end{tabular}

Fonte: Elaborada pelos autores 
ciatura) ter dado ênfase às disciplinas pedagógicas em detrimento de disciplinas ambientais, desconsiderando que a Educação Ambiental é, antes de tudo, educação, e poderia ter sido abordada em disciplinas pedagógicas.

Já as professoras que afirmam ter discutido o tema, indicam ter visto Educação Ambiental nas disciplinas de Ecologia e Botânica, quando o professor discutiu questões relacionadas a como se portar em ambientes naturais, discussão essa que não caracteriza uma abordagem que possa ser considerada Educação Ambiental, como a entendida neste trabalho.

Essas professoras afirmam ainda terem discutido sobre o tema nas disciplinas de Didática das Ciências e Estágio Supervisionado (licenciatura), quando desenvolveram trabalhos sobre conscientização ambiental e consumo consciente na escola. Aqui já percebemos o início de um debate que leva em consideração aspectos socioculturais relacionados ao ambiente natural.

A abordagem da temática ambiental nos estágios, durante a formação do professor, é um aspecto importante a ser considerado, pois, é nesse espaço que o futuro professor pode realizar a articulação entre as diferentes áreas do conhecimento que compõem o saber ambiental.

Em relação aos formandos, três deles afirmam, inicialmente, que não tiveram contato com o tema na graduação e 1 entende que "teve, mas nada específico". Com o decorrer da entrevista, os formandos indicam algum contato com a temática durante o curso, e dois apresentam o trabalho de conclusão de curso (TCC) como o aspecto de relação com a temática (isso só no último ano do curso).

Em relação às disciplinas citadas, uma formanda indica que discutiu sobre a temática nas aulas de didática e sociologia, quando os professores trouxeram textos que a abordavam, porém ela não conseguia lembrar o conteúdo do texto. Essa resposta confirma dados encontrados anteriormente no questionário realizado com a classe. Naquele momento, alguns dos alunos indicaram que o debate sobre Educação Ambiental foi realizado nas aulas de sociologia.

Outra formanda, em seu discurso, assinala ter discutido sobre Educação Ambiental na disciplina de ecologia, porém ela deixa claro que considera ecologia sinônimo de Educação Ambiental. Reproduzimos, abaixo, um trecho de sua fala para evidenciar seu entendimento: "mas eu tive uma matéria [...] ecologia que me chamou bastante a atenção assim me deu um "up" e eu falei "epa" eu tenho que ver um pouquinho mais isso, isso é Educação Ambiental (Intervenção: o que a professora falou que você considerou que estava relacionado com Educação Ambiental?) que assim tem vários animais que precisam daquela certa mata e então tá acabando aquela mata em Piracicaba".

Como discutido anteriormente, ecologia não é sinônimo de Educação Ambiental, embora a área possa organizar debates importantes para Educação Ambiental. Porém, como constatado anteriormente no primeiro questionário do trabalho, $29 \%$ dos professores entrevistados acreditam que discutiram sobre a temática nessa disciplina. Para Tozoni-Reis (2008), as oportunidades de reflexão, oferecidas na graduação, sobre as diferentes referências teóricas da Educação Ambiental, são poucas do ponto de vista quantitativo e superficiais do ponto de vista qualitativo, o que pode resultar nas ideias apresentadas pelos formandos.

A partir desses resultados, apresentamos algumas ideias sobre como repensar a formação universitária que leve em conta uma formação ambiental, especialmente nas licenciaturas. Com base na constatação da inércia universitária, Morin (2001) defende uma reforma da universidade. Essa reforma, como pretendida pelo autor, deverá incluir uma reorganização geral para a instauração de faculdades, departamentos etc., destinados às ciências que já reali- 
A percepção do professor de Biologia ...

zaram uma união em torno de um núcleo organizador sistêmico, que pode ser Ecologia, Ciências da Terra e Cosmologia. Para o autor:

A Ecologia científica, as ciências da Terra, a Cosmologia são efetivamente ciências que tem por objeto não uma área ou um setor, mas um sistema complexo: o ecossistema e, mais amplamente a biosfera, para a Ecologia; o sistema Terra, para as ciências da Terra; e a estranha propensão do Universo a formar e destruir sistemas galáxicos e solares, para a Cosmologia. (MORIN, 2001, p. 83)

Morin (2001) imagina, também, que nessa reforma seja possível criar, em cada universidade, um centro de pesquisas sobre os problemas da complexidade e da transdisciplinaridade. A nosso ver, o surgimento de grandes programas de reflexão interdisciplinar dentro das universidades põe em relevo as grandes questões ambientais, dando a elas um tratamento epistemológico complexo que é importante para a formação de pessoas que contribuam, de alguma maneira, com o equacionamento da crise ambiental.

Já para Leff (2002), o que a problemática ambiental propõe às universidades (quanto à formação de recursos humanos) transcende a criação de um espaço formado pela integração das disciplinas tradicionais. A incorporação do saber ambiental vai além de um requerimento de atualização dos currículos universitários. O saber ambiental constrói-se "por um conjunto de processos de natureza diferente, cuja diversidade de ordens ontológicas, de racionalidades, de interesses e de sentidos não pode estar contida num modelo global, por mais holístico e aberto que este seja" (LEFF, 2002, p. 164). Ainda para Leff (2002), cada ciência, cada disciplina, impõe suas condições teóricas e institucionais para a produção e internalização de um saber ambiental, num processo desigual e heterogêneo. O que pode ser comum a todas é a necessidade da elaboração de métodos pedagógicos para a transmissão desse saber ambiental e a busca de métodos interdisciplinares, capazes de integrar a percepção fragmentada que temos do mundo.

O Artigo 9 ${ }^{\circ}$ Parágrafo Único, da Lei no 9.795/99 sobre Educação Ambiental, diz "que os professores em atividade devem receber formação complementar em suas áreas de atuação, com o propósito de atender adequadamente ao cumprimento dos princípios e objetivos da Política Nacional de Educação Ambiental” (BRASIL, 1999). Já o artigo $2^{\circ}$ da mesma Lei indica que a Educação Ambiental é "um componente essencial e permanente da educação nacional, devendo estar presente, de forma articulada, em todos os níveis e modalidades do processo educativo, em caráter formal e não-formal" (BRASIL, 1999), indicando, assim, a importância da formação na área.

Indo mais longe, não é lógico, ainda, que se exijam, de outros profissionais, atitudes que considerem essa complexidade dos sistemas se eles, também, não foram assim formados. Como exigir de um engenheiro preocupações com materiais naturais, planejamento ecológico, impacto ambiental local e global, se os valores considerados pela sociedade estão centrados na relação custo - benefício, apenas no que se refere aos aspectos econômicos? Como diz Molero (1999, p. 87): "Como é que se pretende integrar a Educação Ambiental na escola sem preparar antes os professores e sem conscientizar os pais e os políticos?".

Mesmo se considerarmos que a educação sozinha não dê cabo dos problemas ambientais, ela é, em médio prazo, a estratégia principal na construção e implementação de princípios 
que possam formar cidadãos e professores com outra subjetividade ambiental. Mas temos de superar a formação meramente técnica e instrumental dos graduandos na universidade.

Novamente de acordo com Leff (2001), a educação relativa ao ambiente concebe-se, muitas vezes, apenas como um treinamento em proteção ambiental ou uma instrução que dê base para um comportamento responsável em relação à natureza. Segundo o autor, isso não basta e, atualmente, são incipientes os programas de formação ambiental "orientados para construção de uma racionalidade alternativa, capaz de promover, mobilizar e articular os processos naturais, tecnológicos e sociais que abram as opções para outro desenvolvimento" (LEFF, 2001, p. 205). Retomando as ideias de Tozoni-Reis (2001, p. 45), atualmente:

A formação dos educadores ambientais no ensino superior se dá de forma assistemática, resumindo-se praticamente a três tipos de ação desconectada: tratamento de temas ambientais nas disciplinas afins, disciplinas optativas de Educação Ambiental e formação educativo pedagógica - nas diferentes especialidades - oferecida pelas disciplinas da área de Educação nas licenciaturas.

Assim, podemos considerar que existe a presença da temática ambiental em algumas atividades nas licenciaturas (em particular, na Licenciatura em Biologia), porém, ainda não há, de acordo com a autora, muitas oportunidades de reflexão sobre as diferentes concepções de relação homem-natureza.

Outro conceito que podemos apresentar, e que está relacionado com a formação (equivocada) de professores em relação à temática ambiental, é a dispedagogia ambiental. Para Gouvêa (2006, p. 5), a dispedagogia ambiental é "uma das consequências do processo equivocado da formação de professores sem o compromisso com a ação emancipatória e com a ética da profissionalidade e da autonomia".

Para a autora, a dispedagogia ambiental pode ser entendida como a falta de um projeto educacional que enfatize a importância dos aspectos político, social, cultural, teórico e prático da educação na construção do entendimento da complexidade ambiental. Isso faz com que o professor acredite que, se ele desenvolver atividades pontuais, desvinculadas da realidade sociocultural (coleta seletiva, horta etc.), em algumas aulas, já estará trabalhando Educação Ambiental. Assim, a dispedagogia ambiental:

[...] faz com que a Educação Ambiental perca suas finalidades, descaracterizando-se enquanto processo educativo permanente e contínuo, uma vez que se torna acrítica e reprodutora, deixando de lado tanto os fundamentos da pedagogia que busca responder aos desafios de nosso tempo, como os fundamentos da própria Educação Ambiental, que visa fomentar novas atitudes críticas e éticas nos indivíduos e na coletividade. (GOUVEA, 2006, p. 6)

Podemos considerar aqui que é importante a formação de professores capazes de promoverem mudanças nas escolas onde atuam. Assim, a formação de professores que privilegie a construção de um saber ambiental deve acontecer numa perspectiva crítica e emancipatória, atrelada a referenciais teóricos que explicitem a complexidade da Educação Ambiental. 
Hoje, pela urgência dos nossos problemas, talvez seja necessário que as universidades e os cursos de formação de professores institucionalizem, num primeiro momento, a Educação Ambiental como disciplina, e se preocupem, também, em incluir a dimensão ambiental em todo o currículo.

Mesmo parecendo essa inclusão (Educação Ambiental como disciplina curricular) contraditória em relação a alguns princípios discutidos (como o da transdisciplinaridade) e a Lei 9795/99, que, no seu artigo 10, diz que "a Educação Ambiental não deve ser implantada como disciplina especifica no currículo de ensino" (BRASIL, 1999), a inclusão da área como disciplina pode institucionalizar um importante debate para formação dos futuros professores de biologia. Além disso, a mesma Lei (9795/99) indica que "nos cursos de pós-graduação, extensão e nas áreas voltadas aos aspectos metodológicos da Educação Ambiental, quando se fizer necessário, é facultada a criação de disciplina especifica" (BRASIL, 1999). Acreditamos que a formação do professor de biologia necessita desses "aspectos metodológicos" já que, muitas vezes, os professores são cobrados por competências que não desenvolveram em sua formação.

Hoje, percebemos que aquilo que ficou a cargo de todos acabou não sendo feito por ninguém, assim, acreditamos que uma disciplina organizaria as discussões epistemológicas necessárias para formação do futuro professor de Biologia.

Sabemos das limitações do saber disciplinar, porém, entendemos, também, que as dificuldades enfrentadas pelo saber disciplinar na compreensão de mundo (e dos problemas ambientais mundiais) são dificuldades postas à concepção positivista de conhecimento, assim, a superação fundamental não é a da matriz disciplinar, mas a do paradigma positivista (MACEDO, 1999).

O mundo vem percebendo os limites da extrema especialização em todas as áreas. Para Macedo (1999), percebemos, hoje, que as disciplinas científicas tradicionais tornaram-se incapazes de atuar, levando à criação de novas especialidades híbridas. Além disso, as fronteiras entre as ciências naturais e sociais vêm sendo muito questionadas, bem como a fronteira entre conhecimento científico e senso comum. A criação de disciplinas que agreguem conhecimentos de várias disciplinas (e de áreas distintas) pode auxiliar na compreensão da realidade ambiental, além de fundamentar teoricamente o futuro professor para seu trabalho junto aos estudantes de Ensino Médio.

Num primeiro momento, nos cursos de graduação e pós-graduação, uma das maneiras de incluir a dimensão ambiental na formação de futuros professores seria inclúi-la, inicialmente, como disciplina. No Brasil existem vários exemplos dessa inclusão, onde podem confluir os debates necessários à formação de um professor crítico, que pense a realidade socioambiental como um processo de construção social. Na região pesquisada, podemos citar: o caso da Escola Superior de Agricultura Luiz de Queiróz da Universidade de São Paulo (ESALQ/ USP, Piracicaba, SP, Brasil), com a disciplina optativa "Projeto em Educação Ambiental", do departamento de Ciências Florestais, coordenada pelo prof. dr. Marcos Sorrentino; e o caso da Universidade Federal de São Carlos (UFSCar, São Carlos, SP, Brasil) - com a disciplina optativa "Educação Ambiental", coordenada pela profa. dra. Haydée Torres Oliveira. Na Universidade Estadual de Campinas (Unicamp, Campinas, SP, Brasil), a disciplina Educação Ambiental, a cargo do prof. Sandro Tonso, também é um exemplo da inserção na graduação.

Para finalizar, podemos considerar que alguns enfoques curriculares devem estar presentes na discussão sobre o papel das universidades em relação à incorporação da dimensão 
ambiental. Para Gonzáles e Gaudiano (2000 apud SANTOS; SATO, 2003), esses enfoques envolvem:

a) um eixo de formação epistemológica, que fortaleça a capacidade dos estudantes para interpretar suas realidades (global-local) e construir os conhecimentos fundamentais da área;

b) um eixo de formação crítico-social, favorecendo a compreensão da complexidade ambiental e de seus problemas com bases políticas, históricas, sociais e culturais, e a relação do pensamento complexo com a realidade local, entendendo a influência do pensamento linearfragmentado na construção de ações que não consideram o todo;

c) um eixo de formação ecológico-ambiental, que proporcione o conhecimento das bases das dinâmicas e dos processos vitais da natureza, com o cuidado de não cair novamente no reducionismo de se considerar que uma Educação Ambiental é apenas uma educação ecológica;

d) um eixo de formação pedagógica, que auxilie os estudantes a construírem um novo discurso como professores, para intervenção local, com estratégias educativas que proporcionem a formação de sujeitos críticos capazes de participação e de formação de outros sujeitos.

Nesse sentido, a Educação Ambiental dos futuros professores de biologia pode contribuir para gerar as capacidades necessárias para "compreender a causalidade múltipla dos fatos da realidade e para inscrever a consciência ambiental e a ação social nas transformações do mundo atual que levarão a um desenvolvimento sustentável, democrático e equitativo" (LEFF, 2001, p. 259).

Pensar a formação de professores de biologia, como educadores ambientais, nos cursos de graduação em ciências biológicas das universidades, significa ter como referência a ideia de totalidade (ambiental, política, pedagógica, social, científica etc.) na diversidade que essas áreas possuem. Para isso, a transdisciplinaridade pode ser o princípio que estruturará essa nova formação.

Mas isso não é uma tarefa simples, pois o educador ambiental deve ser capaz de promover a articulação entre as diferentes áreas do conhecimento que compõem o saber ambiental, e estar apto para identificar as zonas de não-resistência entre as diferentes áreas, estabelecendo comunicação para que possa compreender e atuar de forma significativa no processo de gestão de uma realidade complexa, sempre com o objetivo de superar os problemas ambientais que afligem nossa realidade (GUIMARÃES, 2004).

Outra dificuldade reside no fato de que "não se pode reformar a instituição sem uma prévia reforma das mentes, mas não se podem reformar as mentes sem uma prévia reforma das instituições" (MORIN, 2001, p. 99). Para o autor, a universidade moderna, que rompeu com a universidade medieval, nasceu no início do século XIX, e agora precisa ser reformada. Mas a reforma começará - como todas as reformas - de maneira periférica e marginal.

São várias as sugestões e ideias para a inserção de atividades que contribuam com o desenvolvimento de um saber ambiental junto aos alunos da graduação. Não pretendemos "receitas", mas, alguns autores já nos indicam possibilidades para essa inserção (Quadro 1). 
A percepção do professor de Biologia ...

Quadro 1. Possibilidades da inserção da temática ambiental na formação inicial dos professores de Biologia.

Possibilidades da inserção da temática ambiental na formação inicial dos professores de Biologia

Atividades interdisciplinares entre departamentos e áreas do saber (MORIN, 2001)

Reorganização geral dos departamentos em torno de um núcleo sistêmico (MORIN, 2001)

Criação de centros de pesquisas sobre complexidade e transdisciplinaridade; reorientação de pesquisas (MORIN, 2000, 2001; LEFF, 2001, 2002)

Reelaboração de conteúdos (ambientalização das disciplinas) (LEFF, 2001; 2002)

Elaboração de metodologias pedagógicas interdisciplinares (LEFF, 2001; 2002) e dialógicas (REIGOTA, 2001, 2008)

Criação de disciplinas/ áreas de pesquisa híbridas (MACEDO, 1999; MORIN, 1990, 2001)

Criação de disciplinas específicas (CONSELHO FEDERAL DE BIOLOGIA, 2008) que podem ser um espaço dialógico e da práxis (SORRENTINO, 1995)

Fonte: Elaborada pelos autores

A sistematização acima procura promover a discussão sobre a construção de um saber ambiental capaz de preparar os professores para reelaborarem as informações que recebem e trabalharem nas incertezas do mundo moderno, para que possam transmitir e decodificar, para os alunos, a expressão dos significados sobre o meio ambiente nas suas múltiplas determinações e intersecções. Para isso, a ênfase deve ser a capacitação para se perceberem as relações entre as áreas e como um todo, enfatizando-se uma formação local/global, buscando marcar a necessidade de se enfrentar a lógica da exclusão e das desigualdades (JACOBI, 2003).

Essas ideias podem ser um começo de reflexão sobre o tema para melhorar a formação dos futuros professores de biologia. Possíveis reformulações ou inovações curriculares podem ser implementadas daqui para frente. Esta missão passa pela responsabilidade de todos os docentes e discentes pertencentes ao curso estudado e, também, de outros cursos de ciências biológicas.

O futuro é um planeta desconhecido, onde o que ignoramos é infinitamente maior do que aquilo que conhecemos: Qualquer passo nesse planeta deve ser inspirado por uma combinação original de prudência e audácia (MORIN, 1990). É essa combinação que propomos quando pensamos em uma nova formação ambiental para os professores de Biologia. 
Guimarães, S. S. M.; Inforsato, E. C.

\section{Referências}

BARDIN, L. Análise de conteúdo. Lisboa: Edições 70, 1977.

BRASIL. Presidência da República. Lei no 9.394, de 20 de dezembro de 1996. Estabelece as diretrizes e bases da educação nacional. Brasilia, 1996. Disponível em: <http:// www.planalto.gov.br/ccivil_03/Leis/L9394.htm>. Acesso em: 01 dez. 2008.

Presidência da República. Lei $\mathbf{n}^{\circ} 9.795$ de 27 de abril de 1999. Dispõe sobre a educação ambiental, institui a Política Nacional de Educação Ambiental e dá outras providências. Brasília, 1999. Disponível em: < http://www.planalto.gov.br/ccivil_03/LEIS/ L9795.htm>. Acesso em: 01 fev. 2009.

BURSZTYN, M. Meio ambiente e interdisciplinaridade: desafios ao mundo acadêmico. Desenvolvimento e Meio Ambiente, Curitiba, n. 10, p. 67-76, jul./dez. 2004. Disponível em: <http://hdl.handle.net/10482/9778>. Acesso em: 01 jul. 2008.

BURSZTYN, M. (Org.). Ciência, ética e sustentabilidade: desafios ao novo século. São Paulo: Cortez; Brasília: UNESCO, 2001.

CONSELHO FEDERAL DE BIOLOGIA. Parecer CFAP no. 01/2008 - GT Revisão Currículos: proposta para carga horária mínima e tempo de integralização para curso de bacharelado em ciências biológicas (presencial). Brasília, 2008. Disponível em: <http:// www.crbio01.gov.br $/ \mathrm{cms} /$ index.php? secao $=69 \&$ subsecao $=0 \&$ resumo $=1>$. Acesso em: 01 dez 2008.

DÉCADA da educação das Nações Unidas para um desenvolvimento sustentável 20052014: documento final do esquema internacional de implementação. Brasília: UNESCO, 2005.

DIAS, G. F. Educação ambiental: princípios e práticas. São Paulo: Gaia, 2004.

GOUVÊA, G. R. R. Rumos da formação de professores para a educação ambiental.

Educar em Revista, Curitiba, n. 27, p. 163-179, 2006. Disponível em: <http:// www.scielo.br/scielo.php?script $=$ sci_pdf\&pid $=$ S010440602006000100011\&lng=en\&nrm=iso\&tlng=pt $>$. Acesso em: 05 jan. 2009.

GUIMARÃES M. A formação de educadores ambientais. Campinas: Papirus, 2004.

JACOBI, P. Educação ambiental, cidadania e sustentabilidade. Cadernos de Pesquisa, São Paulo, n. 118, p. 189-205, mar. 2003. Disponível em: <http://www.scielo.br/pdf/cp/n118/ 16834.pdf>. Acesso em: 01 jul. 2008.

LAYRARGUES, P. P. Identidades da educação ambiental brasileira. Brasília: Diretoria de Educação Ambiental, Ministério do Meio Ambiente, 2004.

LEFF, E. Epistemologia ambiental. 2. ed. São Paulo: Cortez, 2002.

Saber ambiental: sustentabilidade, racionalidade, complexidade e poder.

Petrópolis: Vozes, 2001. 
A percepção do professor de Biologia ...

LEROY, J-P.; PACHECO, T. Dilemas de uma educação em tempos de crise. In: LOUREIRO, C. F. B.; LAYRARGUES, P. P.; CASTRO, R. S. de (Org). Pensamento complexo, dialética e educação ambiental. São Paulo: Cortez, 2006. p. 30-71.

LIMA, G. F. da C. Crise ambiental, educação e cidadania: os desafios da sustentabilidade emancipatória. In: LOUREIRO, C. F. B.; LAYRARGUES, P. P.; CASTRO, R. S. de (Org.). Educação ambiental: repensando o espaço da cidadania. São Paulo: Cortez, 2002. p. $109-142$.

MACEDO, E. F. de. Parâmetros curriculares nacionais: a falácia de seus temas transversais. In: MOREIRA, A. F. B. (Org.). Currículo: políticas e práticas. Campinas, Papirus, 1999. p. 43-58.

MOLERO, F. M. Educación ambiental. Madrid: Síntesis, 1999.

MORALES, A. G. M. O processo de formação em educação ambiental no ensino superior: trajetória dos cursos de especialização. Revista Eletrônica do Mestrado em Educação Ambiental, Rio Grande, v. 18, jan./jun. 2007. Disponível em: <http://www.remea.furg.br/ indvol18.php>. Acesso em: 25 mar. 2008.

MORIN, E. A cabeça bem-feita. Rio de Janeiro: Bertrand Brasil, 2001.

Ciência com Consciência. Rio de Janeiro: Bertrand Brasil, 2000.

Introdução ao pensamento complexo. 2. ed. Lisboa: Instituto Piaget, 1990.

ODUM, E. P. Ecologia. Rio de Janeiro: Guanabara Koogan, 1988.

PORTO, E.; SIMÕES, R.; MOREIRA, W. W. Corporeidade e ação profissional na reabilitação: (des)encontros. Revista Brasileira de Ciências do Esporte, Campinas, v. 25, n. 3, p. 101-116, maio 2004.

REIGOTA, M. Meio ambiente e representação social. São Paulo: Cortez, 2001.

. Cidadania e educação ambiental. Psicologia e Sociedade, Belo Horizonte, v. 20, p. 61-69, 2008. Número especial.

RIOJAS, J. A complexidade ambiental na universidade. In: LEFF, E. A. Complexidade ambiental. São Paulo: Cortez, 2006. p. 217-240.

ROHDE, G. M. Mudanças de paradigma e desenvolvimento sustentado. In:

CAVALCANTI, C. Desenvolvimento e natureza: estudos para uma sociedade sustentável. 3. ed. São Paulo: Cortez, 2001. p. 41-53.

SANTOS, B. de S. Pela mão de Alice: o social e o político na pós-modernidade. São Paulo: Cortez, 2001.

SANTOS, J. E. dos; SATO, M. Universidade e ambientalismo: encontros não são despedidas. In: SANTOS, J. E.; SATO, M. A contribuição da educação ambiental à esperança de Pandora. São Carlos: RiMa, 2003. p. 31-50. 
Guimarães, S. S. M.; Inforsato, E. C.

SOFFIATI, A. Fundamentos filosóficos e históricos para o exercício da ecocidadania e da ecoeducação. In: LOREIRO, C. F. B. et al. Educação ambiental: repensando o espaço da cidadania. São Paulo: Cortez, 2002. p. 23-68.

SORRENTINO, M. Educação ambiental e universidade: um estudo de caso. 1995. 263 f. Tese (Doutorado em Educação) - Faculdade de Educação, Universidade de São Paulo, São Paulo, 1995.

TOZONI-REIS, M. F. C. Educação ambiental: natureza, razão e história. Campinas: Autores Associados, 2008.

Artigo recebido em 05/09/2011. Aceito em 21/01/2012. 